Research Article

\title{
Biofilm Formation and Detection of Fluoroquinolone- and Carbapenem-Resistant Genes in Multidrug-Resistant Acinetobacter baumannii
}

\author{
María-Guadalupe Avila-Novoa, Oscar-Alberto Solís-Velázquez, \\ Daniel-Eduardo Rangel-López, Jean-Pierre González-Gómez, \\ Pedro-Javier Guerrero-Medina, and Melesio Gutiérrez-Lomelí
}

\begin{abstract}
Laboratorio de Alimentos, Departamento de Ciencias Médicas y de la Vida, División de Desarrollo Biotecnológico, Universidad de Guadalajara, Centro Universitario de la Ciénega. Av. Universidad 1115, Col. Linda Vista, 47820 Ocotlán, Jalisco, Mexico
\end{abstract}

Correspondence should be addressed to Melesio Gutiérrez-Lomelí; mele.gtz@gmail.com

Received 29 June 2019; Accepted 3 December 2019; Published 20 December 2019

Academic Editor: Bruno Pozzetto

Copyright (c) 2019 María-Guadalupe Avila-Novoa et al. This is an open access article distributed under the Creative Commons Attribution License, which permits unrestricted use, distribution, and reproduction in any medium, provided the original work is properly cited.

\begin{abstract}
Acinetobacter baumannii is an important opportunistic pathogen that shows resistance to cephalosporins, penicillins, carbapenems, fluoroquinolones, and aminoglycosides, the multiresistance being associated with its ability to form biofilms in clinical environments. The aim of this study was to determine biofilm formation and its potential association with genes involved in antibiotic resistance mechanisms of $A$. baumannii isolates of different clinical specimens. We demonstrated $100 \%$ of the $A$. baumannii isolates examined to be multidrug resistant (MDR), presenting a $73.3 \%$ susceptibility to cefepime and a $53.3 \%$ susceptibility to ciprofloxacin. All A. baumannii isolates were positive for $b l a_{\mathrm{OXA}-51}, 33.3 \%$ being positive for $b l a_{\mathrm{OXA}-23}$ and ISAba1, and $73.3 \%$ being positive for gyrA. We found $86.6 \%$ of $A$. baumannii strains to be low-grade biofilm formers and $13.3 \%$ to be biofilm negative; culturing on Congo red agar (CRA) plates revealed that $73.3 \%$ of the A. baumannii isolates to be biofilm producers, while $26.6 \%$ were not. These properties, combined with the role of $A$. baumannii as a nosocomial pathogen, increase the probability of $A$. baumannii causing nosocomial infections and outbreaks as a complication during therapeutic treatments and emphasize the need to control A. baumannii biofilms in hospital environments.
\end{abstract}

\section{Introduction}

A. baumannii is an important opportunistic nosocomial pathogen that causes epidemic pneumonia, urinary tract infections, septicemia, and meningitis. Susceptibility of $A$. baumannii isolates to carbapenems, third- or fourth-generation cephalosporins, fluoroquinolones, and aminoglycosides is less than $30 \%$, which presents a key challenge for empirical therapeutic choice; inappropriate treatments have clearly been associated with increased mortality and healthcare costs [1-3]. The SENTRY Antimicrobial Surveillance Program in 2017 [4] had reported the overall highest frequency of extensively multidrug-resistant (MDR) A. baumannii isolates to occur in Europe (66.4\%), followed by Latin America (61.5\%), Asia-Pacific (60.8\%), and North America (38.8\%), based on a total of 15,491 A. baumannii group (ACBg) isolates collected from over 200 medical locations between 1997 and 2016. Acinetobacter sp. is much more prevalent, presenting higher rates of antimicrobial resistance in Latin America than in other regions. An important mechanism of resistance for MDR strains of A. baumannii is linked to their ability to produce biofilms [5]. Therefore, A. baumannii, especially MDR ones, has gradually gained attention as a human pathogen in hospital environment [6]. Recent studies have reported the biofilmforming ability of $A$. baumannii strains to be related to major virulence factors, promoting bacterial persistence and chronicity in a specific manner, distinct from the MDR 
phenotypes. In addition, quorum sensing, which is a communication mechanism used by bacteria to recognize population density fluctuations and control gene expression [7], has been shown to be associated with biofilm formation by A. baumannni [8-10]. Among the different A. baumannii virulence factors, the most important is their ability to produce biofilms and their survival in hospital environments, which is related to their high degree of antibiotic resistance $[11,12]$. Therefore, this study aimed to investigate clinical A. baumannii isolates in terms of biofilm formation and their potential association with genes involved in antibiotic resistance mechanisms.

\section{Materials and Methods}

2.1. Bacterial Strains and Antibiotic Sensitivity Testing. Different clinical specimens obtained during the month of September 2018, including wounds, urinary catheters, blood, tracheal secretions, bronchoalveolar lavages, and sputum, were inoculated onto blood agar and MacConkey agar plates for $24 \mathrm{~h}$ at $33^{\circ} \mathrm{C}$. Of the 40 bacterial isolates recovered from these clinical specimens, 15 strains of A. baumannii were selected for further studies. The A. baumannii strains were identified based on standard bacteriological tests including Gram staining, oxidase and catalase activity, motility, liquefaction of gelatin, lysine decarboxylase, ornithine decarboxylase, citrate utilization, oxidative/fermentative $(\mathrm{O} / \mathrm{F})$ glucose tests, and growth ability at $44^{\circ} \mathrm{C}$ [13]. The findings were confirmed using PCR based on the intergenic spacer region of the 16S-23S rRNA genes [14]. Patterns of resistance and/or susceptibility were determined using the agar diffusion method, according to the American Clinical Laboratory Standardization Committee (CLSI) [15]. The antibiotics used were cefepime (FEP: $30 \mu \mathrm{g}$ ), ciprofloxacin (CIP: $5 \mu \mathrm{g}$ ), amikacin (AMK: $30 \mu \mathrm{g}$ ), piperacilin-tazobactam (PTZ: $100 / 10 \mu \mathrm{g}$ ), trimethoprim-sulfamethoxazole (SXT: 2.5/23.75 $\mu \mathrm{g}$ ), imipenem (IPM: $10 \mu \mathrm{g}$ ), erythromycin (E: $15 \mu \mathrm{g}$ ), dicloxacillin (DC: $1 \mu \mathrm{g}$ ), and cloxacillin (CX: $1 \mu \mathrm{g}$ ) (BD BBL "Sensi-Disc"). The isolates were cultured on Mueller Hinton agar plates (BD Diagnostic Systems) inoculated with a bacterial suspension equal to $0.5 \mathrm{McF}$ arland and incubated at $37^{\circ} \mathrm{C}$ for $24 \mathrm{~h}$. Diameters of the zone of inhibition were interpreted with reference to the standards set by the CLSI to determine whether the bacterium was susceptible (S), intermediate (I), or resistant (R) to the tested drugs [15]. Isolates resistant to at least three classes of antibiotics were defined as multidrug-resistant $A$. baumannii (MDR-AB) [16]. A. baumannii ATCC 19606 was used as the positive control [17].

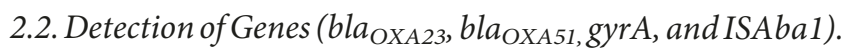
Genomic DNA extraction from A. baumannii was performed using the protocol described by $\mathrm{Pu}$ et al. [18]. Detection of the group of OXA-carbapenemases (bla and bla OxA-51-like$_{\text {) }}$ was performed as reported by Woodford et al. [19]. The conditions used were as follows: $5 \mathrm{~min}$ at $94^{\circ} \mathrm{C}$, followed by 30 cycles of $45 \mathrm{~s}$ at $94^{\circ} \mathrm{C}, 1 \mathrm{~min}$ at $52^{\circ} \mathrm{C}$, and $1 \mathrm{~min}$ at $72^{\circ} \mathrm{C}$, and a final extension of $6 \mathrm{~min}$ at $72^{\circ} \mathrm{C}$. Amplification of DNA gyrase A subunit ( $g y r A$ ) was performed according to the protocol described by de la Fuente et al. [20]. The conditions used were as follows: $3 \mathrm{~min}$ at $96^{\circ} \mathrm{C}$, followed by 24 cycles of $15 \mathrm{~s}$ at $96^{\circ} \mathrm{C}, 30 \mathrm{~s}$ at $50^{\circ} \mathrm{C}$, and $90 \mathrm{~s}$ at $70^{\circ} \mathrm{C}$, and a final extension of $5 \mathrm{~min}$ at $70^{\circ} \mathrm{C}$. ISAbal promoter was detected according to the protocol described by Segal et al. [21]. The conditions used were as follows: $5 \mathrm{~min}$ at $95^{\circ} \mathrm{C}$, followed by 35 cycles of $45 \mathrm{~s}$ at $94^{\circ} \mathrm{C}, 45 \mathrm{~s}$ at $56^{\circ} \mathrm{C}$, and $3 \mathrm{~min}$ at $72^{\circ} \mathrm{C}$, and a final extension of $5 \mathrm{~min}$ at $72^{\circ} \mathrm{C}$. Table 1 lists the primers used for the detection of $b l a_{\text {OXA23 }}, b l a_{\text {OXA51 }}$, gyrA, and ISAba1. A. baumannii ATCC 19606, Pseudomonas aeruginosa ATCC 15442, and Escherichia coli ATCC 25922 were used as reference strains for quality control.

2.3. Phenotypic Analysis of Biofilms. Phenotypic characterization was carried out by culturing the isolates on Congo red agar (CRA), as described by Arciola et al. [22]. Three replicates were performed for each strain.

2.4. Semiquantitative Adherence Assay. Ability of the strains to form biofilms was investigated by culturing them in 96well flat-bottomed microtiter polystyrene plates as described by Kouidhi et al. [23]. For each strain, three wells of the microtiter plate were filled with $200 \mu \mathrm{L}$ bacterial suspension in tryptic soy broth (TSB; BD Diagnostic Systems) with $0.25 \%$ glucose $(\mathrm{w} / \mathrm{v})(\mathrm{TSB}+0.25 \% \mathrm{G})$. The plates were then incubated at $37^{\circ} \mathrm{C}$ for $24 \mathrm{~h}$. Wells filled with broth medium (TSB $+0.25 \% \mathrm{G})$ were used as negative controls and $A$. baumannii ATCC 19606 was used as the positive control. The content of each well was subsequently aspirated and washed thrice with phosphate-buffered saline (PBS; $7 \mathrm{mM}$ $\mathrm{Na}_{2} \mathrm{HPO}_{4}, 3 \mathrm{mM} \mathrm{NaH} \mathrm{PO}_{4}$, and $130 \mathrm{mM} \mathrm{NaCl}, \mathrm{pH} 7.4$ ) to remove the planktonic bacteria. The attached bacteria were fixed with $95 \%$ ethanol for $5 \mathrm{~min}$, after which the plates were emptied and left to dry. The plates were stained with $100 \mu \mathrm{L}$ of $1 \%(\mathrm{w} / \mathrm{v})$ crystal violet solution (Hycel, Zapopan, Jalisco, Mexico) per well for $5 \mathrm{~min}$. The excess stain was rinsed off with sterile distilled water, and the microtiter plates were airdried. Optical density of each well was measured at $570 \mathrm{~nm}$ $\left(\mathrm{OD}_{570}\right)$, using a Multiskan FC (Thermo Fisher Scientific Inc., Madison, WI, USA). Biofilm formation was interpreted as highly positive $\left(\mathrm{OD}_{570} \geq 1\right)$, low-grade positive $\left(0.1 \leq \mathrm{OD}_{570}<1\right)$, or negative $\left(\mathrm{OD}_{570}<0.1\right)$.

\section{Results}

Of the 40 strains, 15 strains of $A$. baumannii were detected from the clinical samples. Isolates of $A$. baumannii presented a pattern of $100 \%$ resistance $(15 / 15)$ to dicloxacillin, cloxacillin, piperacillin/tazobactam, and erythromycin, followed by $66.6 \%$ to sulfamethoxazole/trimethoprim (10/15), $60 \%$ to amikacin (9/15), $46.6 \%$ to ciprofloxacin (7/15), and $40 \%$ to imipenem (6/15). The susceptibility test in this study confirmed A. baumannii isolates to be $73.3 \%$ susceptible to cefepime (11/15), 53.3\% to imipenem and ciprofloxacin (8/ $15)$, and $33.3 \%$ to trimethoprim-sulfamethoxazole $(5 / 15)$ (Figure 1). 
TABLE 1: Sequences of primers used for PCR in this study.

\begin{tabular}{|c|c|c|c|}
\hline Genes & Primers & Sequences $\left(5^{\prime}-3^{\prime}\right)$ & Product sizes (base pairs) \\
\hline gyrA & $\begin{array}{l}\text { GyrA-F } \\
\text { GyrA-R }\end{array}$ & $\begin{array}{l}5^{\prime} \text {-AAATCTGCCCGTGTCGTTGGT-3' } \\
5^{\prime} \text {-GCCATACCTACGGCGATACC-3 }\end{array}$ & 343 \\
\hline blaOXA-23 & $\begin{array}{l}\text { OXA-23-like F } \\
\text { OXA-23-like R }\end{array}$ & $\begin{array}{c}5^{\prime} \text {-GATCGGATTGGAGAACCAGA-3' } \\
5^{\prime} \text {-ATTTCTGACCGCATTTCCAT-3 }\end{array}$ & 501 \\
\hline blaOXA-51 & $\begin{array}{l}\text { OXA-51-like F } \\
\text { OXA-51-like R }\end{array}$ & $\begin{array}{l}5^{\prime} \text {-TAATGCTTTGATCGGCCTTG-3' } \\
5^{\prime} \text {-TGGATTGCACTTCATCTTGG-3' }\end{array}$ & 353 \\
\hline ISAbal & $\begin{array}{l}\text { ISAba } 1 \mathrm{~F} \\
\text { ISAba } 1 \mathrm{R}\end{array}$ & $\begin{array}{c}\text { 5'-CACGAATGCAGAAGTTG-3' } \\
5^{\prime} \text {-CGACGAATACTATGACAC-3' }\end{array}$ & 549 \\
\hline
\end{tabular}

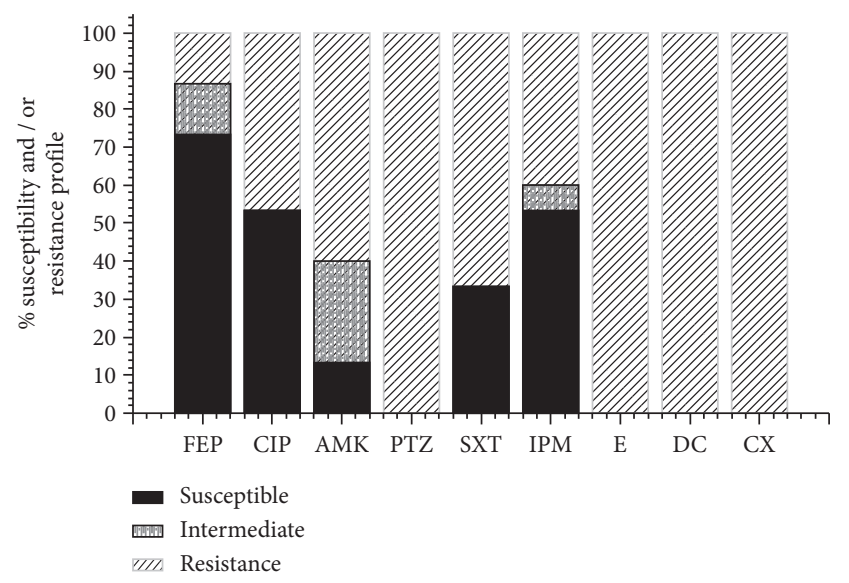

FIgURE 1: Antimicrobial resistance pattern of Acinetobacter baumannii to different antibiotics. FEP, cefepime; CIP, ciprofloxacin; AMK, amikacin; PTZ, piperacillin-tazobactam; STX, trimethoprim-sulfamethoxazole; IMP, imipenem; E erythromycin; DC, dicloxacilin; CX, cloxacilin.

Overall, $100 \%(15 / 15)$ of the A. baumannii isolates examined were MDR; four of them (A. baumanni-7, 8, 11, and 12) were resistant to eight and nine antibiotics, and two of them were susceptible to cefepime (Table 2). In the isolates of A. baumannii-3 and A. baumannii-8, four genes associated with resistance to imipenem and ciprofloxacin were detected. The genes detected by PCR were $b l a_{\text {OXA-51 }}, b l a_{\text {OXA-23, }}$, ISAba1, and gyrA in 100\% (15/15), 33.3\% (5/15), 33.3\% (5/ $15)$, and $73.3 \%(11 / 15)$ of the $A$. baumannii isolates, respectively (Table 2$)$. In $46.6 \%(7 / 15)$ of isolates resistant to ciprofloxacin, gyrA was detected (Figure 1, Table 2). Finally, the $\mathrm{OD}_{570}$ results showed $86.6 \%(13 / 15)$ of the $A$. baumannii strains to be low-grade biofilm formers $\left(0.1 \leq \mathrm{OD}_{570}<1\right)$ and $13.3 \%(2 / 15)$ to be biofilm negative $\left(\mathrm{OD}_{570}<0.1\right)$. On CRA, $73.3 \%(11 / 15)$ of the A. baumannii isolates were biofilm producers (Figure 2), while 26.6\% (4/15) were not (Figure 3).

\section{Discussion}

A. baumannii is a nosocomial pathogen causing multiple pathologies, where biofilm plays a role in the colonization during infection, thus providing an opportunity for $A$. baumannii to develop drug resistance. In this study, $100 \%$ of A. baumannii isolates were resistant to a wide range of antibiotic groups, including third-generation cephalosporins, fluoroquinolones, aminoglycosides, and carbapenems
(Figure 1). Carbapenems are a subgroup of beta-lactams, among which imipenem treatment was confirmed to be effective. However, many current studies have reported increasing resistance to imipenem and ciprofloxacin. DiDomenico et al. [10] found A. baumannii isolates from patients with colonized skin ulcers to have $75 \%$ resistance to imipenem, 75\% resistance to trimethoprim-sulfamethoxazole, and 91\% resistance to ciprofloxacin. Addi-Ali et al. [12] showed $92 \%$ of $A$. baumannii clinical isolates to be resistant to ciprofloxacin and $68 \%$ to be resistant to imipenem. Results of the current study (bla $a_{\text {OXA-51 }}(100 \%)$, bla $a_{\text {OXA-23 }}(33.3 \%)$, ISAbal (33.33\%), and gyrA (73.3\%)) are consistent with those of other studies, which had reported the most prevalent carbapenem hydrolyzing $\beta$-lactamases genes in A. baumannii to include bla $a_{\mathrm{OXA}-51}(83-100 \%)$ and bla $a_{\text {OXA-23 }}(59-96 \%)[16,24,25]$. Therefore, the most prevalent mechanism underlying the resistance of $A$. baumannii to carbapenem antibiotics is the production of OXA-type $\beta$-lactamases, and their resistance to quinolones is related to alterations in the target enzymes GyrA and ParC $[13,26]$. However, the rapid emergence of resistance to aminoglycosides in clinical isolates of Acinetobacter has been linked to their ability to acquire resistance through transposons, plasmids, and integrons; several factors, such as geographical region, misuse of antibiotics, and inappropriate prescription of aminoglycosides, can play a significant role in the prevalence of aminoglycoside resistance genes $[16,27]$. One of the most important mechanisms in the development of an MDR strain is the bacterial biofilm formation, which has attracted extensive study in recent years, since A. baumannii clinical isolates possess a strong ability to form biofilms, which in turn is associated with a significant increase in the antibiotic resistance of the bacteria [17]. Antimicrobial susceptibility testing showed $100 \%$ of the A. baumannii strains to be MDR, having the ability to form biofilms. Thus, the ability of MDR A. baumannii strains to form biofilms, which limit the diffusion of antibiotics to the site of action due to its components or alter the phenotypes or genotypes of the strains, favors resistance. Babapour et al. [28] had shown $92 \%$ of the biofilm-forming A. baumannii clinical isolates from patients with nosocomial infections in three hospitals in Tehran to be MDR, and $86 \%$ to be extensively drug-resistant. Biofilm formation, a factor contributing to the virulence of A. baumannii, is associated with long-term persistence in hospital environments [29]. Yang et al. [30] had argued that the factors leading to enhanced antibiotic resistance in the biofilm phenotype include 
TABLE 2: Characteristics of the multidrug resistance of Acinetobacter baumannii to different antibiotics.

\begin{tabular}{|c|c|c|}
\hline Strains & Multidrug resistance & Genes \\
\hline A. baumannii-1 & CIP-AMK-DC-CX-E & $b l a_{O X A-51}+b l a_{O X A-23}+g y r A$ \\
\hline A. baumannii-2 & AMK-DC-CX-SXT-E-IPM & $b a_{O X A-51}+$ ISA $b a 1$ \\
\hline A. baumannii-3 & CIP-DC-CX-PTZ-SXT-E-IPM & $b l a_{O X A-51}+b l a_{O X A-23}+$ ISA $b a 1+g y r A$ \\
\hline A. baumannii-4 & DC-CX-E & $b l a_{O X A-51}+g y r A$ \\
\hline A. baumannii-5 & DC-CX-PTZ-E & $b l a_{O X A-51}+g y r A$ \\
\hline A. baumannii-6 & DC-CX-PTZ-SXT-E & $b l a_{O X A-51}$ \\
\hline A. baumannii-7 & CIP-AMK-DC-CX-PTZ-SXT-E-IPM & $b l a_{O X A-51}+g y r A$ \\
\hline A. baumannii-8 & FEP-CIP-AMK-DC-CX-PTZ-SXT-E-IPM & $b l a_{O X A-51}+b l a_{O X A-23}+$ ISA $b a 1+g y r A$ \\
\hline A. baumannii-9 & FEP-DC-CX-PTZ-SXT-E-IPM & $b l a_{O X A-51}+b l a_{O X A-23}+$ ISAba1 \\
\hline A. baumannii-10 & CIP-DC-CX-PTZ-E & $b l a_{O X A-51}+g y r A$ \\
\hline A. baumannii-11 & CIP-AMK-DC-CX-PTZ-SXT-E-IPM & $b l a_{O X A-51}+g y r A$ \\
\hline A. baumannii-12 & CIP-AMK-DC-CX-PTZ-SXT-E-IPM & $b l a_{O X A-51}+\mathrm{ISA} b a 1+g y r A$ \\
\hline A. baumannii-13 & AMK-DC-CX-PTZ-SXT-E & bla $a_{O X A-51}+$ gyrA \\
\hline A. baumannii-14 & AMK-DC-CX-PTZ-SXT-E & $b l a_{O X A-51}+g y r A$ \\
\hline A. baumannii-15 & AMK-DC-CX-PTZ-SXT-E & $b l a_{O X A-51}+b l a_{O X A-23}$ \\
\hline
\end{tabular}

FEP, cefepime; CIP, ciprofloxacin; AMK, amikacin; PTZ, piperacillin-tazobactam; STX, trimethoprim-sulfamethoxazole; IMP, imipenem; E, erythromycin; DC, dicloxacillin; CX, cloxacillin.

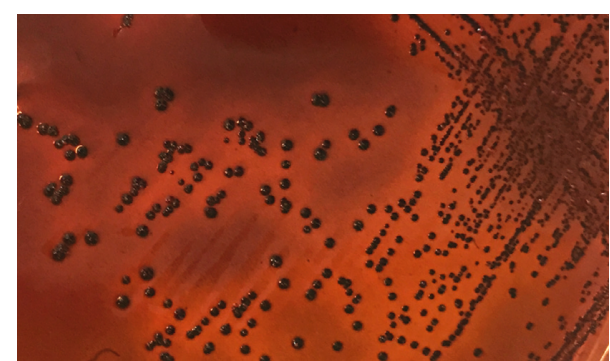

FIGURE 2: CRA plate test: black colonies of the slime-producing Acinetobacter baumannii.

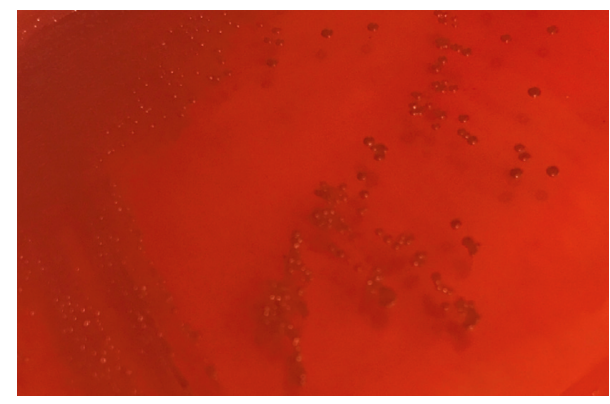

FIGURE 3: CRA plate test: red colonies of the non-slime-producing Acinetobacter baumannii.

impaired drug diffusion due to microbial aggregations, overexpression of the exopolymeric substance (EPS) matrix, alterations in microbial phenotypic and genotypic features due to stress responses, and physiological heterogeneity due to physicochemical gradients and persisters. However, biofilm formation depends on an interaction between three main components: the bacterial cells, the attachment surface, and the surrounding medium [31].

A limitation of this study was the lack of serotyping data for the isolates of A. baumannii or components of the extracellular matrix (exopolysaccharides, eDNA, proteins, and lipids) of multicellular communities, such as the biofilms formed by nosocomial pathogens. Biofilm composition provides a basis for the development of better strategies to reduce sources of contamination in the hospital setting.

Overall, this could lead to the incorporation of new therapeutic strategies that take into account the behavior of sessile cells and the mechanisms of antimicrobial resistance in A. baumannii strains of different origin, with the aim to incorporate or modify the therapeutic treatment schemes used in the control of this nosocomial pathogen or implement cleaning and disinfection procedures to improve hospital environments.

\section{Conclusions}

In the majority of the isolates of multidrug-resistant $A$. baumannii, bla $a_{\mathrm{OXA}-51}+$ bla $_{\mathrm{OXA}-23}$ were detected as the determinant factor for carbapenemic resistance having a direct relation with biofilm formation. These studies provide useful information for new therapeutic regimes in $A$. baumannii infections.

\section{Data Availability}

The data used to support the findings of this study are included within the article.

\section{Conflicts of Interest}

The authors declare that they have no conflicts of interest.

\section{References}

[1] K. Z. Vardakas, P. I. Rafailidis, A. A. Konstantelias, and M. E. Falagas, "Predictors of mortality in patients with infections due to multi-drug resistant gram negative bacteria: the study, the patient, the bug or the drug?" Journal of Infection, vol. 66, no. 5, pp. 401-414, 2013.

[2] M. D. Zilberberg, B. H. Nathanson, K. Sulham, W. Fan, and A. F. Shorr, "Carbapenem resistance, inappropriate empiric treatment and outcomes among patients hospitalized with 
Enterobacteriaceae urinary tract infection, pneumonia and sepsis," BMC Infectious Diseasses, vol. 17, no. 1, p. 279, 2017.

[3] J. Zhang, C. Zhao, H. Chen et al., "A multicenter epidemiology study on the risk factors and clinical outcomes of nosocomial intra-abdominal infections in China: results from the Chinese antimicrobial resistance surveillance of nosocomial infections (CARES) 2007-2016," Infection and Drug Resistance, vol. 11, pp. 2311-2319, 2018.

[4] SENTRY Program, https://www.jmilabs.com/data/posters/ ECCMID2018-SENTRY-Acinetobacter.pdf.

[5] O. Azizi, F. Shahcheraghi, H. Salimizand et al., "Molecular analysis and expression of bap gen in biofilm-forming multi drug-resistant Acinetobacter baumannii," Reports of Biochemistry \& Molecular Biology, vol. 5, no. 1, pp. 62-72, 2016.

[6] L. C. Antunes, P. Visca, and K. J. Towner, "Acinetobacter baumannii: evolution of a global pathogen," Pathogens and Disease, vol. 71, no. 3, pp. 293-301, 2014.

[7] Y. Du, T. Li, Y. Wan, P. Liao, and P. Liao, "Signal moleculedependent quorum-sensing and quorum-quenching enzymes in bacteria," Critical Reviews in Eukaryotic Gene Expression, vol. 24, no. 2, pp. 117-132, 2014.

[8] N. Bhargava, P. Sharma, and N. Capalash, "Quorum sensing inAcinetobacter: an emerging pathogen," Critical Reviews in Microbiology, vol. 36, no. 4, pp. 349-360, 2010.

[9] D. Anbazhagan, M. Mansor, G. O. Yan et al., "Detection of quorum sensing signal molecules and identification of an autoinducer synthase gene among biofilm forming clinical isolates of Acinetobacter spp," PloS One, vol. 7, no. 7, Article ID e36696, 2012.

[10] E. G. Di-Domenico, I. Farulla, G. Prignano et al., "Biofilm is a major virulence determinant in bacterial colonization of chronic skin ulcers independently from the multidrug resistant phenotype," International Journal of Molecular Sciences, vol. 18, no. 5, Article ID E1077, 2017.

[11] P. Espinal, S. Martí, and J. Vila, "Effect of biofilm formation on the survival of Acinetobacter baumannii on dry surfaces," Journal of Hospital Infection, vol. 80, no. 1, pp. 56-60, 2012.

[12] A. Abdi-Ali, S. Hendiani, P. Mohammadi, and S. Gharavi, "Assessment of biofilm formation and resistance to imipenem and ciprofloxacin among clinical isolates of Acinetobacter baumannii in Tehran," Jundishapur Journal of Microbiology, vol. 7, no. 1, Article ID e8606, 2014.

[13] K. Aliakbarzade, S. Farajnia, A. Karimi Nik, F. Zarei, and A. Tanomand, "Prevalence of aminoglycoside resistance genes in Acinetobacter baumannii isolates," Jundishapur Journal of Microbiology, vol. 7, no. 10, Article ID e11924, 2014.

[14] T.-L. Chen, L.-K. Sin, R. C.-C. Wu et al., "Comparison of onetube multiplex PCR, automated ribotyping and intergenic spacer (ITS) sequencing for rapid identification of Acinetobacter baumannii," Clinical Microbiology and Infection, vol. 13, no. 8, pp. 801-806, 2007.

[15] CLSI, Performance Standards for Antimicrobial Susceptibility Testing, Clinical and Laboratory Standards Institute, Wayne, PA, USA, CLSI Supplement M100S, 26th edition, 2016.

[16] M. Gholami, M. Haghshenas, M. Moshiri et al., "Frequency of $16 \mathrm{~S}$ rRNA methylase and aminoglycoside-modifying enzyme genes among clinical isolates of Acinetobacter baumannii in Iran," Iranian Journal of Pathology, vol. 12, no. 4, pp. 329-338, 2017.

[17] X. He, F. Lu, F. Yuan et al., "Biofilm formation caused by clinical Acinetobacter baumannii isolates is associated with overexpression of the AdeFGH Efflux pump," Antimicrobial Agents and Chemotherapy, vol. 59, no. 8, pp. 4817-4825, 2015.

[18] S. Pu, F. Wang, and B. Ge, "Characterization of toxin genes and antimicrobial susceptibility of Staphylococcus aureus isolates from Louisiana retail meats," Foodborne Pathogens and Disease, vol. 8, no. 2, pp. 299-306, 2011.

[19] N. Woodford, M. Ellington, J. Coelho et al., "Multiplex PCR for genes encoding prevalent OXA carbapenemases in Acinetobacter spp," International Journal of Antimicrobial Agents, vol. 27, no. 4, pp. 351-353, 2006.

[20] C. M. de la Fuente, S. P. Dauros, T. H. Bello et al., "Mutaciones en genes gyrA y gyrB en cepas de bacilos gram negativos asiladas en hospitales chilenos y su relación con la resistencia a fluoroquinolonas," Revista Médica de Chile, vol. 135, no. 9, pp. 1103-1110, 2007.

[21] H. Segal, S. Garny, and B. G. Elisha, "Is ISABA-1customized for Acinetobacter?” FEMS Microbiology Letters, vol. 243, no. 2, pp. 425-429, 2005.

[22] C. R. Arciola, L. Baldassarri, and L. Montanaro, "Presence of $i c a A$ and icaD genes and slime production in a collection of staphylococcal strains from catheter-associated infections," Journal of Clinical Microbiology, vol. 39, no. 6, pp. 2151-2156, 2001.

[23] B. Kouidhi, T. Zmantar, H. Hentati, and A. Bakhrouf, "Cell surface hydrophobicity, biofilm formation, adhesives properties and molecular detection of adhesins genes in Staphylococcus aureus," Microbial Pathogenesis, vol. 49, no. 1-2, pp. 14-22, 2010.

[24] M. M. Kock, A. N. Bellomo, N. Storm, and M. M. Ehlers, "Prevalence of carbapenem resistance genes in Acinetobacter baumannii isolated from clinical specimens obtained from an academic hospital in South Africa," Southern African Journal of Epidemiology and Infection, vol. 28, no. 1, pp. 28-32, 2013.

[25] L. Azimi, M. Talebi, M. R. Pourshafie, P. Owlia, and A. R. Lari, "Characterization of carbapenemases in extensively drug resistance Acinetobacter baumannii in a burne care center in Iran," International Journal of Molecular and Cellular Medicine, vol. 4, no. 1, pp. 46-53, 2015.

[26] F. Perez, A. M. Hujer, K. M. Hujer, B. K. Decker, P. N. Rather, and R. A. Bonomo, "Global challenge of multidrug-resistant Acinetobacter baumannii," Antimicrobial Agents and Chemotherapy, vol. 51, no. 10, pp. 3471-3484, 2007.

[27] C. L. Ventola, "The antibiotic resistance crisis: part 1: causes and threats," P\&T, vol. 40, no. 4, pp. 277-283, 2015.

[28] E. Babapour, A. Haddadi, R. Mirnejad, S.-A. Angaji, and N. Amirmozafari, "Biofilm formation in clinical isolates of nosocomial Acinetobacter baumannii and its relationship with multidrug resistance," Asian Pacific Journal of Tropical Biomedicine, vol. 6, no. 6, pp. 528-533, 2016.

[29] S. Y. Ryu, W.-K. Baek, and H. A. Kim, "Association of biofilm production with colonization among clinical isolates of Acinetobacter baumannii," The Korean Journal of Internal Medicine, vol. 32, no. 2, pp. 345-351, 2017.

[30] J. Yang, M. Toyofuku, R. Sakai, and N. Nomura, "Influence of the alginate production on cell-to-cell communication in Pseudomonas aeruginosa PAO1," Environmental Microbiology Reports, vol. 9, no. 3, pp. 239-249, 2017.

[31] R. Van Houdt and C. W. Michiels, "Biofilm formation and the food industry, a focus on the bacterial outer surface," Journal of Applied Microbiology, vol. 109, no. 4, pp. 1117-1131, 2010. 


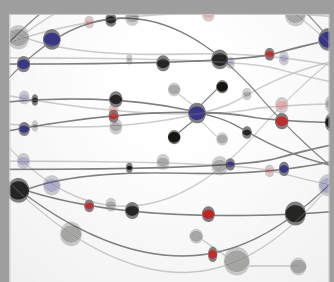

The Scientific World Journal
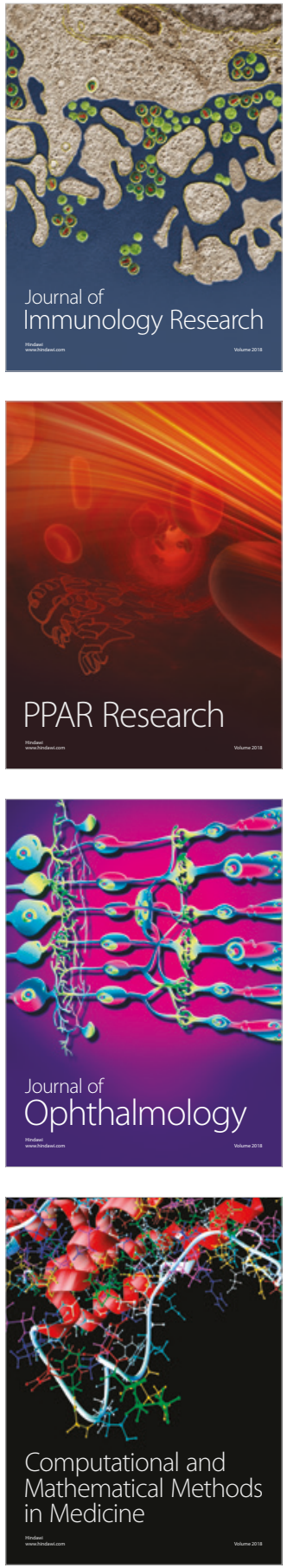

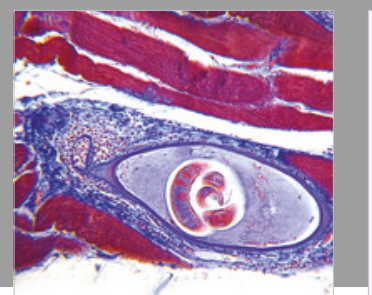

Gastroenterology Research and Practice

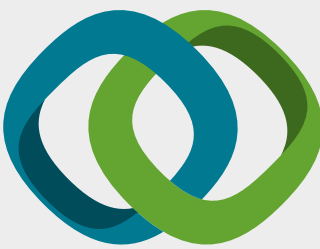

\section{Hindawi}

Submit your manuscripts at

www.hindawi.com
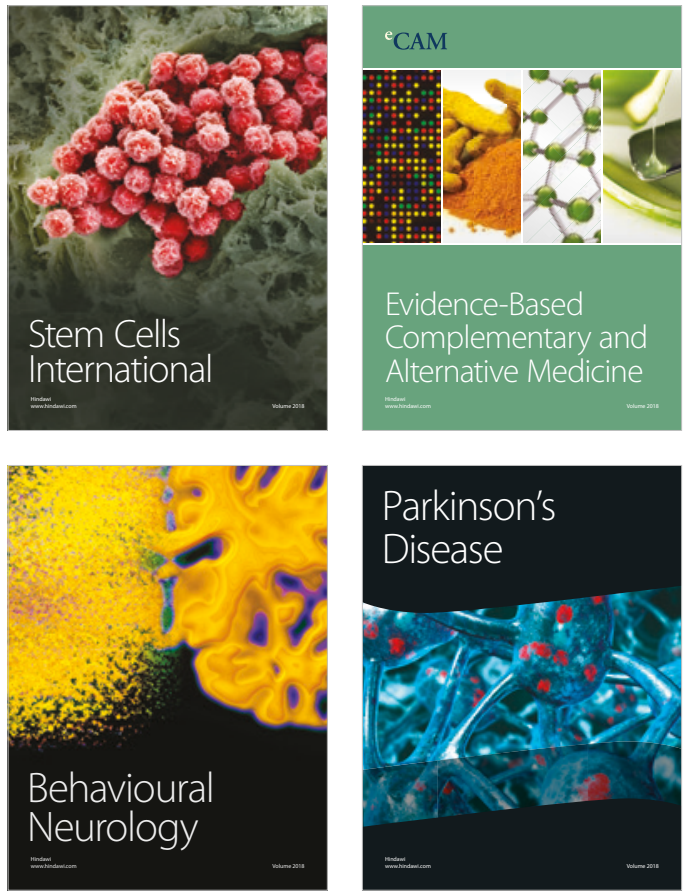

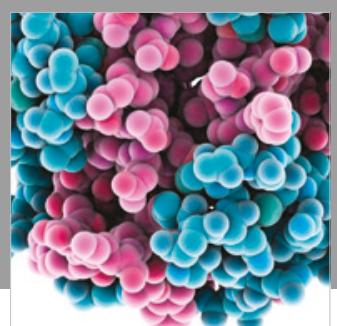

ournal of

Diabetes Research

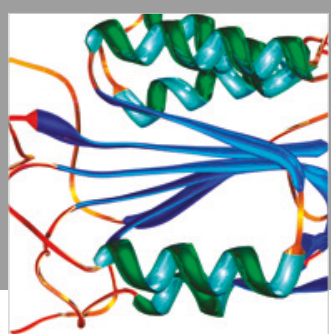

Disease Markers
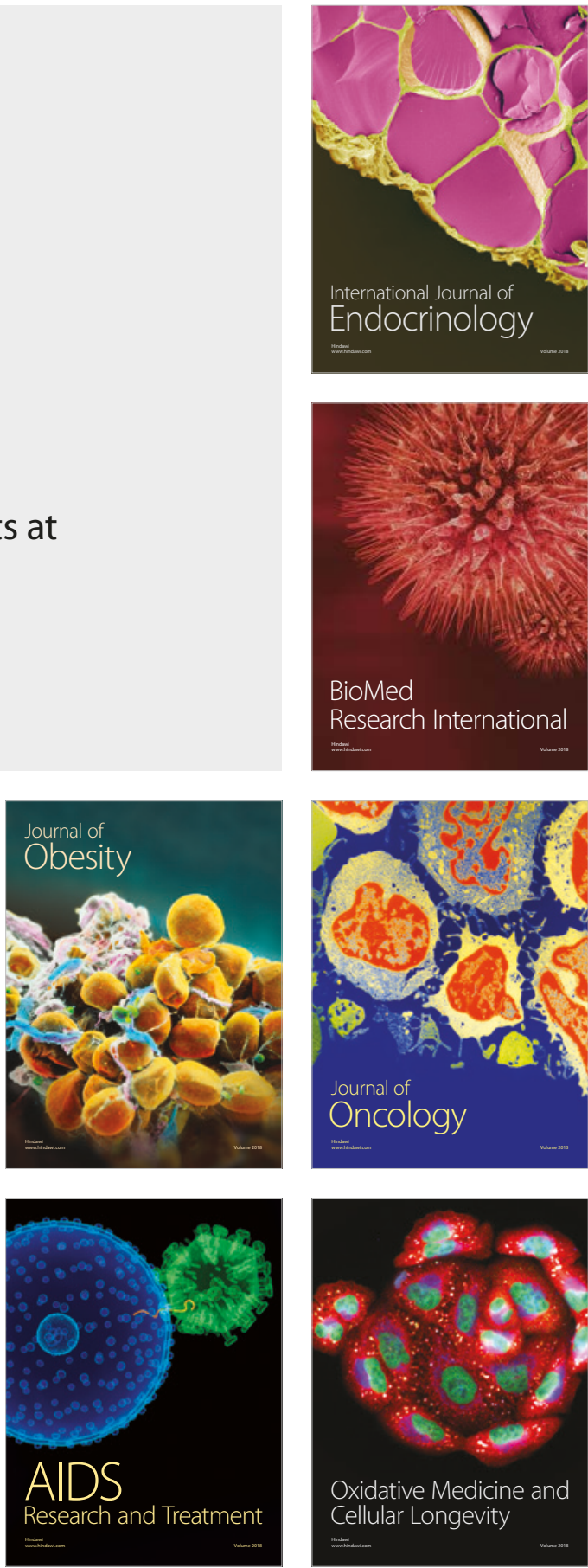